ARTÍCULO

\title{
CLAUDIO SÁNCHEZ-ALBORNOZ, LA EDAD MEDIA CASTELLANA Y LA CONQUISTA DE AMÉRICA REVISIÓN Y CRÍTICA DE UNA POSTURA POLÉMICA
}

\section{CLAUDIO SÁNCHEZ-ALBORNOZ, THE CASTILLIAN MIDDLE AGES AND THE CONQUEST OF AMERICA}

\section{A CRITICAL REVIEW OF A CONTROVERSIAL POSITION}

\section{Martín F. Ríos SALOMA}

Universidad Nacional Autónoma de México Instituto de Investigaciones Históricas / Facultad de Filosofía y Letras riosmartin76@gmail.com

Resumen

En el presente trabajo se analizan las posturas historiográficas del medievalista español Claudio Sánchez-Albornoz a propósito de la conquista de América. El análisis se realiza a partir de textos de naturaleza distinta editados entre 1930 y 1982 con el fin de constatar, por un lado, la permanencia de sus ideas en torno a la proyección de experiencias del pasado medieval hispánico sobre el Nuevo Mundo y, por el otro, el cambio de perspectiva en torno a su valoración sobre el continente americano tras cuatro décadas de exilio en Argentina.

Palabras clave: América; España; Conquista; historia; historiografía; Sánchez-Albornoz.

Abstrac

The present work approaches the Spanish medievalist Claudio Sánchez-Albornoz' historiographical view on the conquest of America. Our analysis is based on Sánchez-Albornoz' dissimilar texts published between 1930 and 1982 in order to assess, on the one hand, the continuance of his own ideas about the extrapolation of Spanish medieval experiences on the New World, and, on the other, his own appraisal of the American continent after his exile in Argentina during four decades.

Keywords: America; Spain; Conquest; history; historiography; Sánchez-Albornoz.

Información del artículo

Recibido: 29 de septiembre de 2019.

Aceptado: 19 de febrero de 2020.

DOI: 10.22201/iih.24485004e.2020.59.70963 
La conquista de México, un debate contemporáneo

El quinto centenario del arribo de Hernán Cortés a las costas del Golfo de México ha sido motivo de conmemoración y discusión por parte de distintas instituciones mexicanas a lo largo del año 2019. También fue motivo de un roce diplomático entre México y España cuando en el mes de marzo la prensa de ambos países se hizo eco de la carta en la que el mandatario mexicano pedía al monarca español una disculpa por la conquista e invitaba a repensar la historia compartida. "La carta enviada por el Presidente López Obrador - afirmaba el secretario de relaciones exteriores mexicano Marcelo Ebrad - a las autoridades españolas es una propuesta de reconciliación histórica. No se funda en el rencor sino en la verdad. No busca conflicto sino encuentro. Las relaciones entre ambos países se mantendrán cordiales y vigorosas." ${ }^{1}$

La polémica intelectual, diplomática y mediática generada por aquella misiva y la multiplicidad de encuentros académicos organizados en torno al tema de la conquista de México muestran hasta qué punto aquel suceso es importante para nuestras sociedades y en qué medida se mantiene vivo. Tal vigencia obliga a los historiadores dedicados a estudiar el proceso de reconocimiento, conquista y colonización de América a ofrecer explicaciones y reflexiones que permitan comprender su significado en el mundo contemporáneo y entender por qué y cómo se ha mantenido como el elemento articulador de los discursos identitarios a ambos lados del mar —bien por aceptación y exaltación, bien por rechazo y menosprecio- en los que se genera no sólo una visión distorsionada del pasado sino un desconocimiento mutuo entre España y México.

La historiografía es un vehículo privilegiado para analizar el proceso de construcción de las identidades nacionales contemporáneas por cuanto ésta tiene como objetivo último estudiar el proceso a través del cual personas, grupos e instituciones seleccionaron algunos acontecimientos del pasado y les dieron un sentido que permitiera, precisamente, construir una identidad colectiva. ${ }^{2}$ Es así que el quinto centenario del inicio de la

${ }^{1}$ Tweet de Marcelo Ebrad, 27 de marzo de 2019. Reproducido en Enrique Sánchez, “Carta de López Obrador a España, propuesta de reconciliación histórica: Ebrard”, Excélsior, 27 de marzo de 2019, https://www.excelsior.com.mx/nacional/carta-de-lopez-obrador-a-espana-propuesta-de-reconciliacion-historica-ebrard/1304129.

${ }^{2}$ Eric Hobsbawm, "Introducción. La invención de la tradición”, en La invención de la tradición, ed. de Eric Hobsbawm y Terence Ranger (Barcelona: Crítica, 2002), 7-21. 
empresa cortesiana ha permitido abrir nuevos debates en torno a los sucesos desencadenados a partir de 1519, dar voz a la multiplicidad de actores que participaron en ellos, resignificar el sentido de muchos de los acontecimientos ya conocidos y, en fin, ampliar la escala de análisis para tomar en cuenta los procesos regionales y mundiales desechando las lecturas localistas o nacionalistas.

Es en este marco en el que me propongo analizar las posturas historiográficas de Claudio Sánchez-Albornoz en torno a la conquista de América como resultado preliminar de un proyecto de investigación más amplio que busca trazar la biografía intelectual de uno de los historiadores españoles más importantes del siglo xx. El prestigio intelectual del que gozó en vida, la importancia política que tuvo como hombre de Estado al servicio de la República - tanto en su país natal como en su prolongado exilio argentino-, así como la enorme difusión que tuvieron sus escritos a ambos lados del Atlántico, lo convierten en un referente intelectual de su tiempo.

En los últimos años, autores como Alejandro García Sanjuan o José Luis Martín han vuelto sobre la obra del insigne abulense con el fin de ponderar la vigencia de sus postulados. En este sentido, en tanto García Sanjuan ha criticado brillantemente a lo largo de sus trabajos recientes el esencialismo que inunda las páginas de España, un enigma histórico, ${ }^{3}$ Martín ha subrayado el gusto por la controversia y la paradoja de don Claudio, sin dejar de remarcar tanto la importancia - y de cierta forma inoperancia- de conceptos como la contextura vital, el carácter temperamental o la evolución y permanencia del estilo de vida hispano, caros al pensamiento de SánchezAlbornoz, como la importancia del trabajo directo sobre las fuentes y su enorme erudición. ${ }^{4}$

Las críticas de ambos medievalistas se suman a las que ya a principios de la década de 1990 se habían presentado en el homenaje organizado por la Universidad de Valladolid con motivo del centenario del natalicio de don

${ }^{3}$ Alejandro García Sanjuán, “La aportación de Claudio Sánchez-Albornoz a los estudios andalusíes”, Revista de Historiografía, n. 2 (2005): 143-153; Alejandro García Sanjuán, "Al-Andalus en el nacionalcatolicismo español: la historiografía de época franquista (19391960)", en El franquismo y la apropiación del pasado, ed. de Francisco Moreno Martín (Madrid: Fundación Pablo Iglesias, 2017), 189-208; Alejandro García Sanjuán "Al-Andalus en la historiografía nacionalcatólica española: Claudio Sánchez-Albornoz”, eHumanista, n. 37 (2017): 305-328.

${ }^{4}$ José Luis Martín, “Claudio Sánchez-Albornoz (1893-1984)”, en Rewriting the Middle Ages in the Twentieth Century, ed. de Jaume Aurell y Francisco Crosas (Turnhout: Brépols, 2005), 149-170. 
Claudio, en las que había comenzado a cuestionarse la explicación totalizadora del sabio abulense como lo indica el propio título del volumen, Sánchez-Albornoz a debate, o las elaboradas por el profesor Miguel Ángel Ladero a finales de la centuria pasada, donde subrayaba que si bien ese esencialismo era ciertamente criticable en nuestros días por no existir el homo hispánico, no debían menospreciarse los esfuerzos de Sánchez-Albornoz por encontrar nuevas explicaciones del ayer de España articuladas en torno a la larga duración braudeliana ni tampoco la forma en que a través de su trabajo como historiador quiso explicar el pasado y no sólo describirlo o enunciarlo. ${ }^{5}$

A más de tres décadas de la muerte de Sánchez-Albornoz, estamos en condiciones de ponderar el conjunto de su obra, la vigencia de sus aportes y la trascendencia de su pensamiento en función no de nuestros propios parámetros, sino de los marcos intelectuales, culturales e historiográficos que le eran propios. En este sentido, revisar sus posturas acerca de la conquista de América permite no sólo enriquecer la discusión en torno al legado albornociano, sino también contribuir al debate en torno a la construcción de las identidades nacionales a partir del discurso historiográfico. Ello resulta aún más relevante cuando a ambos lados del Atlántico - y más allá de las polémicas diplomáticas y del ruido generado por los medios de comunicación masiva- los historiadores profesionales lanzan nuevas miradas sobre el proceso de reconocimiento, conquista y colonización de América y sus profundos significados en los distintos campos del saber histórico.

Claudio Sánchez-Albornoz: historia, política e historiografía

El 26 de agosto de 1980 el historiador español Claudio Sánchez-Albornoz y Menduiña publicó en el diario barcelonés La Vanguardia un texto intitulado "Veleidades islamizantes en Andalucía. Reconquista de la Reconquista", el cual dedicaba el sabio y anciano medievalista "a sus amigos andaluces”. El ensayo fue reproducido posteriormente el 13 de marzo de 1981 por el periódico local El Ideal de Granada y una tercera vez en Madrid en 1983

${ }^{5}$ Reyna Pastor, Carlos Estepa Díez, José A. García de Cortázar y José Luis Abellán, Sánchez-Albornoz a debate. Homenaje de la Universidad de Valladolid con motivo de su centenario (Valladolid: Universidad de Valladolid, 1993); Miguel Ángel Ladero Quesada, “¿Es todavía España un enigma histórico? Releyendo a Sánchez-Albornoz", en Lecturas sobre la España histórica, (Madrid: Real Academia de la Historia, 1998), 317-341. 
por la editorial Rialp en el volumen compilatorio De la Andalucía islámica a la de hoy. ${ }^{6}$

Escrito desde el destierro en Buenos Aires, el artículo no era otra cosa que una férrea crítica a la actitud política de quienes querían manipular la historia y hacer un uso político del ayer al exaltar un idealizado pasado andalusí en el marco de la conformación de la España de las autonomías resultado de la promulgación de la Constitución de $1978 .^{7}$ De esta guisa, don Claudio se lamentaba de que Córdoba estuviese llena de carteles de propaganda islámica, de que el alcalde de aquella ciudad cediese la antigua iglesia del convento de clarisas para establecer una mezquita y de que el alcalde de Granada junto con algunos concejales, se negase a asistir y participar en las fiestas del 2 de enero que conmemoraba la toma de la otrora capital del reino nazarí por los Reyes Católicos. Para el antiguo rector de la Universidad Central, esas "veleidades islamizantes" no eran otra cosa que falacias historiográficas e históricas que reflejaban un enorme desconocimiento de las realidades medievales de la península ibérica, y por ello el madrileño afirmaba con la contundencia que le caracterizaba: "Estoy habituado a la estúpida negativa de que a los largos siglos que median entre la batalla de Covadonga y la rendición de Granada deban llamarse Reconquista. He defendido muchas, muchas veces, la realidad de esa gran aventura cuyas proyecciones históricas han llegado hasta hoy. Sin la Reconquista, nuestra historia moderna sería inexplicable. Porque esa gran

${ }^{6}$ Claudio Sánchez-Albornoz, "Veleidades islamizantes en Andalucía. Reconquista de la Reconquista”, en De la Andalucía islámica a la de hoy (Madrid: Rialp, 1983), 13-25. La información sobre la edición y reimpresiones del texto se ha obtenido cruzando los datos de los distintos libros misceláneos de nuestro autor que lo reproducen. La bibliografía sobre SánchezAlbornoz es abundante; he dado cuenta de ella de manera pormenorizada en Martín Ríos Saloma, "De Europa a América: Claudio Sánchez-Albornoz y la fundación de los Cuadernos de Historia de España”, Medievalismo. Órgano de la Sociedad Española de Estudios Medievales, n. 28 (2018): 235-270, aunque merece la pena rescatar los trabajos más recientes de Fernando Devoto, "Claudio Sánchez-Albornoz y el Anuario de Historia del Derecho Español", Cuadernos de Historia de España, n. 77 (2001-2002): 225-231; María Estela González de Fauve, "Don Claudio Sánchez-Albornoz y el Instituto de Historia de España de Buenos Aires", Cuadernos de Historia de España, n. 77 (2001-2002): 207-211; Martín, "Claudio Sánchez-Albornoz (1893-1984)”; García Sanjuán, “La aportación de Claudio Sánchez-Albornoz...” y “Al-Andalus en el nacionalcatolicismo español...”; y José María López Sánchez, "La escuela histórica del derecho madrileña: Eduardo de Hinojosa y Claudio Sánchez-Albornoz”, Cuadernos de Historia de España, n. 81 (2007): 165-180.

${ }^{7}$ Recientemente Sophie Baby, El mito de la transición pacífica. Violencia y política en España (1978-1982) (Madrid: Akal, 2018), ha analizado minuciosamente los distintos conflictos vividos en el seno de la sociedad española durante los años de la transición. 
aventura afirmó nuestro talante nacional, conquistamos América y fuimos espada de Dios en la tierra".

El enorme prestigio intelectual y político del que gozaba don Claudio en los últimos años de su vida otorgaba a sus textos un peso importante en la opinión pública española - particularmente entre los sectores más conservadores- y permitía que éstos circularan a ambos lados del Atlántico con enorme rapidez gracias a la promoción de editoriales como Espasa-Calpe, Planeta o Rialp. De esta suerte, no es aventurado afirmar que en las bibliotecas de las familias de la clase media ilustrada de países como España, Argentina, México o Chile hubiese uno o más libros salidos de la pluma de Sánchez-Albornoz, y que ello marcara la visión que un público culto pero no especializado pudiera hacerse de la historia de España en la Edad Media y de su proyección sobre el continente americano.

Al iniciar la década de 1980 la visión histórica de Sánchez-Albornoz estaba ciertamente anquilosada y se hallaba anclada en una tradición historiográfica propia de las décadas de 1920 y 1930 del siglo xx que, aunque buscaba acercar a España a las corrientes intelectuales de vanguardia representadas por las tradiciones historiográficas alemana y francesa y su interés en la historia de las instituciones y del Derecho, era en última instancia heredera de la historiografía nacionalista del siglo xIx que tenía como objetivo fundamental definir las esencias patrias y construir un pasado común. ${ }^{9}$ De esta suerte Claudio Sánchez-Albornoz, quien en su juventud y madurez representó la renovación de la escuela histórica española — gracias al patrocinio recibido por parte de la Junta de Ampliación de Estudios, a su pertenencia al Centro de Estudios Históricos, a la introducción de la escuela metódica alemana, a la fundación del Anuario de Historia del Derecho Español, del Instituto de Estudios Medievales en el Centro de Estudios Históricos o de la Monumenta Hispaniae Historica y al desarrollo de la historia comparada tal y como la practicaba Marc Bloch, de quien llegó a ser amigo personal-, fue considerado al final de su vida como un historiador conservador. ${ }^{10}$ Ello resulta sin duda paradójico pues aunque Sánchez-Albornoz se

${ }^{8}$ Sánchez-Albornoz, "Veleidades islamizantes en Andalucía...”, 13-14.

${ }^{9}$ Fernando Wulff, Las esencias patrias. Historiografía e historia antigua en la construcción de la identidad española (siglos XVI-XIX) (Madrid: Crítica, 2003); Martín Ríos Saloma, La Reconquista en la historiografía española contemporánea (Madrid-México: Sílex/Universidad Nacional Autónoma de México, 2013).

${ }^{10}$ Sobre el Centro de Estudios Históricos de Madrid y el papel de la Junta de Ampliación de Estudios véanse los trabajos de José María López Sánchez, Heterodoxos españoles. El Centro 
definió siempre como católico, liberal y anticomunista, su compromiso con el proyecto cultural, educativo y político de la República y la legitimidad del gobierno republicano en el exilio -que llegó a presidir entre 1962 y 1970 - y su negativa a pisar la tierra natal mientras Franco viviera, le obligaron a vivir fuera de España cuarenta años. ${ }^{11}$

A partir de estos elementos históricos, biográficos, políticos, historiográficos y editoriales apenas esbozados, cabe plantearse una pregunta sencilla pero que encierra una enorme complejidad: ¿qué visión tenía Claudio Sánchez-Albornoz de la historia de América y de la conquista del continente americano por parte de las huestes castellanas? Para responder esta interrogante acudiremos a textos de distinta naturaleza - conferencias, artículos periodísticos, ensayos históricos y artículos científicos- que nuestro historiador elaboró a lo largo de su vida. Lamentablemente no existe forma de medir el impacto que sus ideas tuvieron entre los lectores, pero no cabe la menor duda, a tenor de las declaraciones recientes de algunos políticos españoles con motivo de la solicitud de perdón del presidente de México al rey de España y del programa político del partido político ultraderechista Vox, que hay al menos un eco. ${ }^{12}$ Ello no significa, de ninguna manera, que Sánchez-Albornoz fuese ultraderechista ni ideólogo de esos grupos políticos, sino más bien que tales grupos se han apropiado y han reactualizado un discurso histórico, político e historiográfico que hunde sus raíces en el nacional-catolicismo de finales del siglo XıX. ${ }^{13}$

de Estudios Históricos 1910-1936 (Madrid: Marcial Pons, 2006); y “La República de las ciencias y de las letras”, en Política cultural de la segunda República española, ed. de Idoia Muga Castro y José María López Sánchez (Madrid: Pablo Iglesias, 2016). Sobre el derrotero intelectual de Sánchez-Albornoz en sus años de formación, véase Martín Ríos Saloma, "De Europa a América...”; Martín Ríos Saloma, "Claudio Sánchez-Albornoz, profesor de la Universidad Nacional del Litoral (Rosario) (1952-1956)”, Anuario Digital. Escuela de Historia, Facultad de Humanidades y Artes. Universidad Nacional de Rosario, n. 30 (2018): 154-181, https://doi.org/10.35305/aeh.v0i30.254; Martín Ríos Saloma, "Claudio Sánchez-Albornoz y la preocupación por el método o cómo hacer historia medieval desde América Latina”, Anos 90: Revista do Programa de Pós-Graduação em História da Universidade Federal do Rio Grande do Sul, n. 26 (2019): 1-13, https://doi.org/10.22456/1983-201X.88675.

${ }^{11}$ Reyna Pastor de Togneri, "Claudio Sánchez-Albornoz, historiador, maestro y militante”, en Sánchez-Albornoz a debate. Homenaje de la Universidad de Valladolid con motivo de su centenario, Reyna Pastor de Togneri et al. (Valladolid: Universidad de Valladolid, 1993), 9-19.

${ }^{12}$ Armando Tejeda, "Petición de AMLO desata orgullo patrio e insultos racistas en España”, La Jornada, 26 de marzo de 2019.

${ }^{13}$ Martín Ríos Saloma, La Reconquista. Génesis y desarrollo de una construcción historiográfica (s. XVI-XIX) (Madrid-México: Marcial Pons/Universidad Nacional Autónoma de México, 2011). 
Claudio Sánchez-Albornoz y su visión de la conquista de América

La primera incursión de Sánchez-Albornoz en la problemática de la conquista de América tuvo lugar en mayo de 1930, cuando presentó al Congreso de Americanistas celebrado en Sevilla la ponencia intitulada "La Edad Media y la empresa de América". Ese mismo texto fue reproducido en la conferencia homónima que impartió, primero, en la ciudad de Buenos Aires en agosto de 1933 y, después, por invitación del Rector Enrique Levene, en la Universidad de la Plata en el marco del viaje de estudios organizado de manera conjunta por la Institución Cultural Española y la Juta de Ampliación de Estudios cuando nuestro historiador se desempeñaba como Rector de la Universidad Central. El texto fue reeditado en el mismo año de 1933 por la propia Universidad de la Plata y posteriormente en 1943 por la Editorial Sudamericana, edición esta última que sirve de base para nuestro análisis. ${ }^{14}$ Si me detengo en la historia de la conferencia y los espacios en los que fue leída - Sevilla, Buenos Aires, la Plata- y publicada - Argentina- es para subrayar, primero, el interés de Sánchez-Albornoz de entablar un diálogo con los colegas modernistas, aún a sabiendas de que no era experto en la época pero consciente de que no hay un corte radical entre la Edad Media y la Edad Moderna. En segundo término, para poner de relieve la validez universal -o al menos hispánica- que el propio medievalista concedía a sus reflexiones al considerar legítimo presentarlas tanto a la comunidad académica congregada en torno a la ciudad hispalense como a aquélla reunida en las universidades rioplatenses. Por último, el interés que el tema tenía en un país - Argentina- nutrido no sólo por el exilio español procedente de la España en guerra, sino de una comunidad de emigrantes económicos que desde finales del siglo xix había hecho "las Américas". 15

${ }^{14}$ Claudio Sánchez-Albornoz, "La Edad Media y la empresa de América”. En España y el Islam, (Buenos Aires: Sudamericana, 1943). Los datos han sido obtenidos de informaciones dispersas en los escritos autobiográficos del propio Sánchez-Albornoz editados en los diferentes libros misceláneos y en las informaciones que él mismo ofreció en la sección varia del Anuario de Historia del Derecho Español (AHDE). Sobre la conferencia en Sevilla y el primer viaje a Argentina en particular, véanse Claudio Sánchez-Albornoz, "III Congreso Internacional de Geografía e Historia Hispano-Americana”, Anuario de Historia del Derecho Español, n. 7 (1930): 557-559; y Claudio Sánchez-Albornoz, "Las conferencias de Sánchez-Albornoz en la Argentina”, Anuario de Historia del Derecho Español, n. 10 (1933): 515-529.

15 Ariel Guiance, "La historiografía española y el medievalismo americano: SánchezAlbornoz, Américo Castro y la construcción de la identidad nacional a través de la Edad 
En este sentido, es necesario insistir en el relieve e importancia de una editorial como Sudamericana, fundada precisamente por exiliados españoles con la idea de continuar a este lado del Atlántico con su labor cultural y de satisfacer las demandas del mercado latinoamericano en general y del porteño en particular. ${ }^{16}$

Las reflexiones elaboradas por Sánchez-Albornoz en 1930 sobre la conquista de América están llenas de lugares comunes. Especializado en el estudio de la alta Edad Media peninsular y de las instituciones políticas, económicas y sociales del reino astur-leonés, el entonces catedrático de historia Antigua y Medieval de la Universidad Central y flamante Académico Numerario de la Real Academia de la Historia - había sido electo en 1926 - no podía sino poseer conocimientos superficiales. Sin embargo, más allá de la retórica patriótica que impregnaba su discurso y de las generalidades hay un elemento que me parece rescatable: el hecho de considerar la conquista de América como una proyección de las experiencias históricas de la Castilla medieval, y centrar el análisis en cuatro elementos fundamentales: la conquista militar, la conquista espiritual, la colonización y repoblación del territorio y los aspectos jurídicos.

Así pues, el abulense abría su conferencia preguntándose si sería una "audacia imperdonable ver en la empresa americana una prolongación de la Edad Media, una proyección del medioevo hispano en el espacio y en el tiempo y en la reafirmación de las rutas medievales de España”. ${ }^{17}$ Afirmándose como medievalista y consciente de que no era el campo de su especialidad, el alumno dilecto de Eduardo de Hinojosa pedía que no se viese en su aserto "una orgullosa teoría sino una modesta interrogante" y trazaba el esquema de la que sería su interpretación general de la historia de España, la cual le acompañaría hasta la muerte, a saber: que la lucha contra el islam a lo largo de ocho siglos había desviado a España del derrotero histórico natural por el que discurrían las otras naciones europeas y que ello había significado "un atraso de la vida espiritual hispana" respecto de éstas. Así, la conquista de América no podía ser sino "fruto tardío" de las andanadas medievales. “¿Cómo no advertir en el descubrimiento y conquista de

Media”, en La influencia de la historiografía española en la producción americana, ed. de Ariel Guiance (Madrid: Marcial Pons/Instituto de Historia Simancas, 2011), 25-58.

${ }^{16}$ María Teresa Pochat, "Editores y editoriales", en El destierro español en América. Un trasvase cultural, comp. de Nicolás Sánchez-Albornoz (Madrid: Instituto de Cooperación Iberoamericana/Sociedad Estatal del V Centenario, 1991), 163-176.

${ }^{17}$ Sánchez-Albornoz, “La Edad Media y la empresa de América...”, 181. 
América la última edad heroica del mundo occidental, el último periodo de la Edad Media épica?", se preguntaba henchido de amor patrio. Definida por nuestro historiador como "cruzada y aventura" a la vez, la conquista de América por Castilla se distinguía de la romana porque ésta había sido llevada a cabo por el Estado, mientras que aquélla era "la acción dispersa y desconcertada del pueblo castellano". ${ }^{18}$ Para don Claudio, "el espíritu religioso y guerrero, místico y codicioso a la par" eran sentimientos típicamente medievales, ${ }^{19}$ de tal suerte que España había llevado "a las Indias colombinas su medievalismo agrario, religioso y guerrero". ${ }^{20}$

Más allá de esos sentimientos o actitudes existían sin embargo elementos estructurales mucho más importantes en los que - es necesario reconocerlo- se muestra con nitidez la proyección de las experiencias de la vida medieval hispana sobre América: la expansión de la monarquía castellana por el orbe que representaba en sí misma la conquista del Nuevo Mundo, la "fundación de ciudades", la "organización política" de la tierra ganada, "la erección de sedes episcopales y cenobios" y, en fin, "el trasplante [nótese la metáfora médica] de una raza, de una religión, de una lengua y de una cultura". ${ }^{21}$ Así, frente a los "heroicos" hechos de armas, quedaría siempre la "memoria de las despaciosas horas de la colonización." ${ }^{22}$ Este último punto resulta fundamental, pues aunque aún falten casi dos décadas para que Braudel formule su propuesta de la larga duración, el académico de la historia apunta ya a la importancia de los procesos agrarios, es decir, a la ocupación y puesta en valor de los espacios conquistados: "Cada día [asienta] se afirma con más fuerza la idea de que toda la historia medieval de Castilla se resume y cristaliza en una no interrumpida y gigantesca empresa de colonización". ${ }^{23}$ Era precisamente esa experiencia la que permitía a Castilla, a España en realidad, llevar a cabo con éxito la tarea histórica que se le había presentado en el otoño de los siglos medievales.

A decir de nuestro historiador, ninguna otra nación de Europa habría estado preparada para superar con éxito un desafío tan complejo como lo eran la conquista y la colonización americanas y así, "en una curva aérea trazada por cima de los derroteros colombinos, Castilla proyectó su medioevo

\footnotetext{
${ }^{18}$ Sánchez-Albornoz, "La Edad Media y la empresa de América...”, 182-183.

${ }^{19}$ Sánchez-Albornoz, "La Edad Media y la empresa de América...”, 184.

${ }^{20}$ Sánchez-Albornoz, "La Edad Media y la empresa de América...”, 185.

${ }^{21}$ Sánchez-Albornoz, "La Edad Media y la empresa de América...", 185.

${ }^{22}$ Sánchez-Albornoz, "La Edad Media y la empresa de América...”, 186.

${ }^{23}$ Sánchez-Albornoz, "La Edad Media y la empresa de América...”, 186.
} 
más allá de las fronteras españolas". Esa proyección "era la misma empresa" que la experimentada en la España medieval, "con el mismo espíritu de cruzada y de rapiña, con la cruz en lo alto y la bolsa vacía, con codicia de riquezas y de almas, y con la civilización y la libertad occidental que habían de crear el mundo de hoy, en la punta de las espadas y de las lanzas". ${ }^{24}$ Esa acción civilizadora se reflejaría no sólo en el "trasplante" de la lengua y del cristianismo como queda dicho, sino en una serie de instituciones políticas y jurídicas: "Behetrías, encomiendas, cartas de población, privilegios y libertades municipales, adelantamientos, capitanías, colonización monacal y eclesiástica, instituciones fiscales y guerreras” y, por supuesto, "la política asimilista e igualitaria de la corona de Castilla" que, al igual que ya había ocurrido con los castellanos, declaró como "súbditos a los Indios de América y no convirtió en colonias a las tierras conquistadas, sino que las tuvo por prolongación del solar nacional”. ${ }^{25}$

A pesar de los aspectos positivos que la empresa americana tuvo para España, desde el punto de vista de Sánchez-Albornoz, republicano convencido, existió también una consecuencia negativa: perpetuar durante varios siglos más la condición hipertrofiada e inmovilista de España - particularmente del clero y de la monarquía- e inhibir el desarrollo de una burguesía industrial y mercantil debido, precisamente, a la permanencia del orden social estamental de raigambre medieval. No obstante este elemento negativo, el joven académico de la historia concluía su conferencia "en la ciudad más americana de España" constatando "el espíritu medieval con el que se acometió la empresa americana, la prolongación aquende el mar de la labor colonizadora de Castilla y la consecuente perduración de las características políticas, económicas y psicológicas hispanas creadas o afirmadas durante la Edad Media". ${ }^{6}$

El alzamiento de Franco en 1936 contra el gobierno de la República sorprendió a Sánchez-Albornoz en Lisboa cuando se desempeñaba como embajador de su país. ${ }^{27}$ El apoyo del gobierno de Salazar a los militares españoles rebeldes obligó a nuestro historiador a refugiarse en Burdeos, ciudad en la que retomó sus actividades universitarias hasta el verano de

${ }^{24}$ Sánchez-Albornoz, “La Edad Media y la empresa de América...”, 189.

${ }^{25}$ Sánchez-Albornoz, "La Edad Media y la empresa de América...”, 189-191.

${ }^{26}$ Sánchez-Albornoz, "La Edad Media y la empresa de América...”, 199.

${ }^{27}$ Sonsoles Cabeza de Sánchez-Albornoz, Semblanza histórico-política de Claudio SánchezAlbornoz (León: Fundación Universitaria Española/Diputación Provincial de León, 1992), 88-110. 
1940, cuando el avance del ejército alemán sobre la ciudad francesa lo obligó a buscar un nuevo lugar de acogida. He estudiado con detenimiento en otro lugar las circunstancias que llevaron al político e historiador republicano a rechazar la invitación del gobierno de Lázaro Cárdenas para instalarse en México y a desplazarse a Argentina, razón por la que obvio aquí las peripecias. ${ }^{28}$ Baste decir que el 13 de diciembre arribó a la ciudad de Mendoza, al pie de los Andes, y que con el fin de completar sus ingresos como profesor de la Universidad Nacional de Cuyo y matar las muchas horas muertas comenzó a escribir para el diario local Los Andes y para el periódico nacional La Prensa, radicado este último en la capital argentina. ${ }^{29}$

De los más de cuarenta artículos periodísticos que el abulense dio a la luz entre 1940 y 1942, año este último de su instalación definitiva en Buenos Aires, es el que publicó el 22 de julio de 1941 en Los Andes intitulado "Acerca de la enseñanza de la historia de España en Argentina" el que retiene nuestra atención y que fue recogido posteriormente en la antología De Carlomagno a Roosevelt, editada también en 1943 y en la que basamos nuestro análisis. ${ }^{30}$

En ese artículo nuestro historiador se permitía hacer "un reproche" a sus colegas argentinos quienes, a decir del antiguo diplomático, "habían olvidado que la historia argentina estaba integrada por tres siglos de historia de España, y que España se había prolongado a este lado del mar en las tierras del Río de la Plata". 31 "Habéis olvidado, añade, que tenéis vuestras raíces en las tierras y en los llanos de la vieja España. Que vuestros abuelos españoles habían realizado grandes hazañas antes de venir a estas tierras argentinas y que continuaron realizándolas al otro lado del Atlántico mientras colonizaban vuestra patria”. ${ }^{32}$

Sánchez-Albornoz se mostraba comprensivo con el hecho de que la independencia hubiese llevado a los argentinos, y con ellos al resto de las naciones latinoamericanas, a "cortar los vínculos que los unían con la madre patria" y que "en un movimiento de mal humor, volviesen la espalda a su pasado, el pasado de España”, ${ }^{33}$ pero argumentaba también que habían pasado

${ }^{28}$ Ríos Saloma, "De Europa a América...".

${ }^{29}$ Ríos Saloma, "Claudio Sánchez-Albornoz, profesor...”.

${ }^{30}$ Claudio Sánchez-Albornoz (1943), “Acerca de la enseñanza de la Historia de España en Argentina”, en De Carlomagno a Roosevelt (Buenos Aires: Emecé Editores, 1943).

${ }^{31}$ Sánchez-Albornoz (1943), "Acerca de la enseñanza...”, 183.

32 Sánchez-Albornoz, "Acerca de la enseñanza...”, 184.

33 Sánchez-Albornoz, “Acerca de la enseñanza...”, 184. 
muchos años y que las heridas habían cicatrizado y que no era comprensible que no se estudiase la historia española. Y a continuación don Claudio mostraba un enorme desprecio y desconocimiento de las culturas aborígenes en esa voluntad de exaltar lo hispano. Cito en extenso:

Habéis estudiado con interés creciente los restos de las viejas culturas indígenas que vivieron en vuestra tierra argentina, los restos de las pobres culturas indígenas que hallaron aquí vuestros abuelos españoles [...] Tenéis el deber de hacerlo así. No voy a reprochar ese culto a lo indígena. Pero no es menor vuestro deber de estudiar la historia española, vuestra historia, y de enseñarla a vuestra mocedad. Vuestros abuelos no son los indios o lo son en muy reducida proporción. Los héroes de vuestra nacionalidad, que veneráis con muy justo título y cálida devoción [...] todos fueron de pura cepa hispana. No fueron los indios sus abuelos. Sus abuelos hicieron algo más que pobres vasos de ruda cerámica o que toscos templos y primitivas esculturas. ${ }^{34}$

Y a continuación el antiguo rector de la Universidad Central de Madrid enumeraba las grandes realizaciones culturales hispanas hechas por los abuelos españoles de los argentinos, desde el acueducto de Segovia hasta el Escorial, pasando por la mezquita de Córdoba y la Alhambra de Granada, y repasaba superficialmente los distintos elementos culturales de matriz hispana que conformaban la identidad y el ser argentino, desde los nombres de las ciudades y de las calles, hasta la lengua y los apellidos de las grandes familias. Y concluía su artículo lanzando a los argentinos - y a los americanos por extensión - una punzante interrogante: “¿Hasta cuándo habéis de seguir cometiendo ese yerro - yo me atrevería a escribir: ese pecadocontra vosotros mismos: de no enseñar a vuestros hijos la historia de España, vuestra historia?". ${ }^{5}$

Pasados año y medio de estancia en Mendoza, en junio de 1942 SánchezAlbornoz pudo desandar por fin los dos mil kilómetros que separan la ciudad andina de la capital rioplatense y se integró a la Universidad de Buenos Aires, donde fundó el Instituto de Historia de España. Tras dos años de intenso trabajo, el 21 de julio de 1944 apareció el primer número de los Cuadernos de Historia de España, la primera revista científica nacida en América dedicada a la historia española y particularmente al periodo

\footnotetext{
34 Sánchez-Albornoz, “Acerca de la enseñanza...”, 185.

${ }^{35}$ Sánchez-Albornoz, “Acerca de la enseñanza...”, 188.
} 
medieval. En la presentación de la revista, que pretendía situarse a la altura de las grandes revistas europeas de la época, don Claudio escribió:

En estos Cuadernos no vamos a ocuparnos sino del pasado ultra-atlántico de España. La historia española abarca, claro está, la de las gestas, las instituciones, las ideas, el arte y las letras españolas allí donde los españoles alentaron. Mas en América hay multitud de Institutos científicos consagrados a investigar su pasado colonial y no nos proponemos competir con ellos. De intento hemos reducido el campo de nuestros estudios a la historia europea de España, porque venimos a llenar un vacío de la ciencia argentina; un vacío doloroso para los españoles del nuevo continente; un vacío que, pese a muchos americanos, trunca el conocimiento y la comprensión del pretérito de América: el del estudio y la investigación de la historia española en que hallan sus raíces veinte pueblos hispano-americanos.

Al día siguiente de la secesión volvieron todos la espalda a su pasado español e hicieron vocación de ignorarlo. Han cicatrizado las heridas del sangriento desgarrón y ha llegado la hora de cooperar, desde aquí, en el estudio de la historia común, mal conocida aún aquende y allende los mares. ${ }^{36}$

Como puede apreciarse, las ideas vertidas en el artículo mendocino adquirían el cuerpo de un discurso científico que, liberado de pasiones y de patriotismo, venía a señalar una grave carencia de los estudios históricos en Argentina y por extensión en América: el desconocimiento de la historia de España.

La necesidad de gestionar la vida cotidiana —científica y administrativa- del Instituto de Historia de España, la nostalgia por el país lejano, las complicaciones propias de la vida del exiliado a las que se sumaban las de la vida universitaria en la Argentina de las décadas de 1950 y 1960, pero sobre todo el hecho de que el verdadero interés científico de SánchezAlbornoz estuviera centrado en el fin del mundo romano y la alta Edad Media hispánica, explican que a lo largo de casi cuatro décadas nuestro autor no volviese a ocuparse ni en sus artículos científicos ni en sus obras de difusión, tanto ensayos como artículos periodísticos, de la historia americana ni de la proyección de las estructuras medievales sobre el Nuevo Mundo como no fuera de soslayo y de forma casi accidental.

Hubo que esperar hasta 1983, al final de su vida y de sus años de exilio, para que el entonces decano de la Real Academia de la Historia publicara

${ }^{36}$ Claudio Sánchez-Albornoz, “Advertencia”, Cuadernos de Historia de España, n. 1 y 2 (1944): 7-8. 
en el Instituto de Cooperación Iberoamericana radicado en Madrid un último ensayo sobre esta temática intitulado La Edad Media española y la empresa de América, donde con la autoridad que le conferían cuarenta años de exilio y setenta de actividad profesional, ponía su pluma al servicio de la construcción del concepto de Iberoamérica, de la conmemoración del medio milenio del viaje colombino y del gobierno de la transición. ${ }^{37}$

Sin sorpresa alguna, don Claudio, que había escrito el texto en Argentina, reafirmaba las viejas ideas que había enunciado por vez primera en la conferencia pronunciada en Sevilla a la que nos hemos referido más arriba e insistía, una vez más, en la idea de la proyección de las experiencias de la sociedad medieval castellana sobre el mundo Atlántico. La diferencia, sin embargo, radica en el hecho de que la conferencia pronunciada en la vieja Hispalis había sido escrita cuando el joven historiador aún no había conocido América, en tanto que este último ensayo llevaba consigo cuarenta años de experiencia americana. Ello permitía escribir a nuestro autor:

Siempre había sentido personal emoción al meditar sobre ese magno suceso del ayer de la humanidad. Esa emoción creció geométricamente después de vivir cuarenta años a este lado del Atlántico en las tierras que integraron el imperio español de las Indias; de haber recorrido muchos de los países que de él formaron parte desde la Florida a los bellos lagos sureños de la Argentina; de haber oído hablar castellano a todo lo largo y ancho de este mundo nuevo que pueblan trescientos millones de hombres; de haber contemplado prácticas y costumbres hispanas en los más apartados lugares de estas Indias antañonas -algunas presenciadas en el Cuzco me transportaron a mi amada ciudad de Ávila-; de haberme arrodillado ante imágenes de la virgen María junto a grupos de indígenas nietos de los vencidos por Cortés; de ver rendir culto a Santiago desde La Habana a Lima; de comprobar la envidia y el resentimiento que aún anidan en muchos medios cultos e industriales europeos al tropezar con los corolarios actuales de nuestras gestas americanas; de oír hablar mi lengua en la polifacética Argentina por gentes de todos los orígenes nacionales y raciales a ella llegadas... Todo ello todavía hoy, medio millar de años después de que las naves castellanas cruzaran el mar tenebroso... ${ }^{38}$

Como puede apreciarse, los cuarenta años de exilio en el sur del continente americano habían permitido a Sánchez-Albornoz modificar su percepción del mismo y valorar su diversidad cultural y geográfica e incluso

\footnotetext{
${ }^{37}$ Sánchez-Albornoz, La Edad Media española...

${ }^{38}$ Sánchez-Albornoz, La Edad Media española..., 5.
} 
a aquellos indígenas despreciados al momento de su llegada, aunque fuese sólo por su fe católica y su devoción a las imágenes marianas.

Desde esta perspectiva nos parece que su negativa a instalarse de nuevo en España al morir Franco no debe entenderse sólo como una cuestión práctica vinculada a la falta de una propiedad inmobiliaria en la cual pasar sus últimos años - las suyas le habían sido expropiadas durante la guerra civil por el régimen pero sus hijas vívían en Madrid- ni a la falta de unos ingresos permanentes - es cierto que vivía en Argentina con modestia, pero siempre se negó a recibir la pensión que le correspondía como exministro del gobierno y rechazó alguna beca de investigación ofrecida por el régimen- sino que a la luz de este texto puede decirse que, a pesar de la continua añoranza por su Ávila natal y el Madrid de su juventud, ${ }^{39}$ América había conquistado el alma de don Claudio como lo había hecho con tantos aventureros, soldados y conquistadores cinco siglos antes.

\section{Conclusiones}

Sería fácil desde el siglo xxI desestimar las interpretaciones de Claudio Sánchez-Albornoz calificándolas como el reflejo de una visión patriótica y nostálgica producto del prolongado destierro o de una visión historiográfica anquilosada y tradicionalista. Pero lo cierto es que, más allá del tono vehemente que siempre utilizó el que llegase a ser considerado como el "patriarca de los medievalistas españoles", nuestro autor no dejó de señalar a lo largo de toda su vida algo fundamental para la historia americana: la proyección efectiva de las experiencias históricas de la península ibérica desarrolladas a lo largo de la Edad Media sobre el continente americano a partir de 1492. El rigor intelectual que siempre le caracterizó y el profundo conocimiento de la realidad americana le permitieron constatar y resaltar la presencia de numerosos elementos culturales hispanos en nuestro continente, desde el uso de la lengua castellana hasta la religión, pasando por la onomástica, los procesos de ocupación del espacio o los aspectos jurídicos. Ello llevó al sabio medievalista a insistir en el hecho de que la historia

${ }^{39}$ Claudio Sánchez-Albornoz, "Otros tiempos. Requiem por el Madrid de mi juventud”, en Del ayer y del hoy de España (Barcelona: Planeta, 1980), 203-209. A lo largo de su vida Claudio Sánchez-Albornoz escribió numerosos artículos periodísticos en distintos diarios españoles y argentinos que fueron reunidos por su hijo Nicolás Sánchez-Albornoz, “Ávila”, en Claudio Sánchez-Albornoz (Ávila: Diario de Ávila, 1983). 
de España no debía ser considerada por las naciones americanas como una historia ajena, sino, antes bien, como una historia propia o, por mejor decir, como una historia compartida. Una historia compartida cuyos rasgos eran visibles en la cotidianidad sin que ello significara que fuesen superficiales sino que, más bien, eran profundos y de larga data y podían servir como elementos articuladores de una identidad hispana común.

A principios de la década de 1980 cuando Sánchez-Albornoz escribía sus últimos textos se constataba no sólo la división de un mundo bipolar, sino las dificultades de la propia España para gestionar su pasado remoto -el islámico, la conquista de América - y el reciente - la guerra civil y la represión subsecuente-. En consecuencia, el último ensayo de SánchezAlbornoz puede leerse no sólo en claves de la reconciliación de España con su pasado, sino también como una invitación para que a través del conocimiento de la historia española las naciones hispanoamericanas pudieran crear una región unida, fortalecida y bien definida culturalmente que les permitiera hacer frente a los desafíos de un mundo bipolar. A más de treinta años de su muerte, la invitación de Claudio Sánchez-Albornoz para conocer la historia de España en profundidad sigue vigente. Como sigue vigente la imperiosa necesidad de que España, la España de hoy, también conozca la historia y la realidad americanas y no le dé la espalda a su propia historia.

\section{BiBLIOGRAFÍA}

Baby, Sophie. El mito de la transición pacífica. Violencia y política en España (19781982). Madrid: Akal, 2018.

Cabeza de Sánchez-Albornoz, Sonsoles. Semblanza histórico-política de Claudio Sánchez-Albornoz. León: Fundación Universitaria Española/Diputación Provincial de León, 1992.

Devoto, Fernando. "Claudio Sánchez-Albornoz y el Anuario de Historia del Derecho Español.” Cuadernos de Historia de España, n. 77 (2001-2002): 225-231.

García Sanjuán, Alejandro. "Al-Andalus en el nacionalcatolicismo español: la historiografía de época franquista (1939-1960).” En El franquismo y la apropiación del pasado, edición de Francisco Moreno Martín, 189-208. Madrid: Fundación Pablo Iglesias, 2017.

García Sanjuán, Alejandro. "Al-Andalus en la historiografía nacionalcatólica española: Claudio Sánchez-Albornoz.” eHumanista, n. 37 (2017): 305-328. 
García Sanjuán, Alejandro. "La aportación de Claudio Sánchez-Albornoz a los estudios andalusíes.” Revista de Historiografía, n. 2 (2005): 143-153.

González de Fauve, María Estela. "Don Claudio Sánchez-Albornoz y el Instituto de Historia de España de Buenos Aires." Cuadernos de Historia de España, n. 77 (2001-2002): 207-211.

Guiance, Ariel. "La historiografía española y el medievalismo americano: Sánchez-Albornoz, Américo Castro y la construcción de la identidad nacional a través de la Edad Media." En La influencia de la historiografía española en la producción americana, edición de Ariel Guiance, 25-58. Madrid: Marcial Pons/ Instituto de Historia Simancas, 2011.

Hobsbawm, Eric. "Introducción. La invención de la tradición." En La invención de la tradición, edición de Eric Hobsbawm y Terence Ranger, 7-21. Barcelona: Crítica, 2002.

Ladero Quesada, Miguel Ángel. “¿Es todavía España un enigma histórico? Releyendo a Sánchez-Albornoz.” En Lecturas sobre la España histórica, 317-341. Madrid: Real Academia de la Historia, 1998.

López Sánchez, José María. "La escuela histórica del derecho madrileña: Eduardo de Hinojosa y Claudio Sánchez-Albornoz.” Cuadernos de Historia de España, n. 81 (2001): 165-180.

López Sánchez, José María. Heterodoxos españoles. El Centro de Estudios Históricos, 1910-1936. Madrid: Marcial Pons, 2006.

López Sánchez, José María. “La República de las ciencias y de las letras.” En Política cultural de la segunda República española, edición de Idoia Muga Castro y José María López Sánchez, 43-64. Madrid: Editorial Pablo Iglesias, 2016.

Martín, José Luis. “Claudio Sánchez-Albornoz (1893-1984).” En Rewriting the Middle Ages in the Twentieth Century, edición de Jaume Aurell y Francisco Crosas, 149-170. Turnhout: Brépols, 2005.

Pastor de Togneri, Reyna. "Claudio Sánchez-Albornoz, historiador, maestro y militante.” En Sánchez-Albornoz a debate. Homenaje de la Universidad de Valladolid con motivo de su centenario, Reyna Pastor de Togneri, Carlos Estepa Díez, José A. García de Cortázar, y José Luis Abellán, 9-19. Valladolid: Universidad de Valladolid, 1993.

Pastor de Togneri, Reyna, Carlos Estepa Díez, José A. García de Cortázar y José Luis Abellán. Sánchez-Albornoz a debate. Homenaje de la Universidad de Valladolid con motivo de su centenario. Valladolid: Universidad de Valladolid, 1993.

Pochat, María Teresa. "Editores y editoriales." En El destierro español en América. Un trasvase cultural, compilación de Nicolás Sánchez-Albornoz, 163-176. Madrid: Instituto de Cooperación Iberoamericana/Sociedad Estatal del V Centenario, 1991. 
Ríos Saloma, Martín. "Claudio Sánchez-Albornoz, profesor de la Universidad Nacional del Litoral (Rosario) (1952-1956).” Anuario Digital. Escuela de Historia, Facultad de Humanidades y Artes. Universidad Nacional de Rosario, n. 30 (2018): 154-181. https://doi.org/10.35305/aeh.v0i30.254.

Ríos Saloma, Martín. "Claudio Sánchez-Albornoz y la preocupación por el método o cómo hacer historia medieval desde América Latina." Anos 90: Revista do Programa de Pós-Graduação em História da Universidade Federal do Rio Grande do Sul, n. 26 (2019): 1-13. https://doi.org/10.22456/1983-201X.88675.

Ríos Saloma, Martín. “De Europa a América: Claudio Sánchez-Albornoz y la fundación de los Cuadernos de Historia de España." Medievalismo. Órgano de la Sociedad Española de Estudios Medievales, n. 28 (2018): 235-270.

Ríos Saloma, Martín. La Reconquista en la historiografía española contemporánea. Madrid-México: Sílex/Universidad Nacional Autónoma de México, 2013.

Ríos Saloma, Martín. La Reconquista. Génesis y desarrollo de una construcción historiográfica (s. XVI-XIX). Madrid-México: Marcial Pons/Universidad Nacional Autónoma de México, 2011.

Sánchez-Albornoz, Claudio. "Acerca de la enseñanza de la historia de España en Argentina.” En De Carlomagno a Roosevelt, 183-189. Buenos Aires: Emecé Editores, 1943.

Sánchez-Albornoz, Claudio. “Advertencia.” Cuadernos de Historia de España, n. 1 y 2 (1944): 7-9.

Sánchez-Albornoz, Nicolás. “Ávila.” En Claudio Sánchez-Albornoz. Ávila: Diario de Ávila, 1983.

Sánchez-Albornoz, Claudio. "Las conferencias de Sánchez-Albornoz en la Argentina." Anuario de Historia del Derecho Español, n. 10 (1933): 515-529.

Sánchez-Albornoz, Claudio. "III Congreso Internacional de Geografía e Historia Hispano-Americana.” Anuario de Historia del Derecho Español, n. 7 (1930): 557-559.

Sánchez-Albornoz, Claudio. La Edad Media española y la empresa de América. Madrid: Ediciones de Cultura Hispánica del Instituto de Cooperación Iberoamericana, 1983.

Sánchez-Albornoz, Claudio. "La Edad Media y la empresa de América." En España y el Islam, 181-199. Buenos Aires: Sudamericana, 1943.

Sánchez-Albornoz, Claudio. "Otros tiempos. Requiem por el Madrid de mi juventud.” En Del ayer y del hoy de España, 203-209. Barcelona: Planeta, 1980.

Sánchez-Albornoz, Claudio. "Veleidades islamizantes en Andalucía. Reconquista de la Reconquista.” En De la Andalucía islámica a la de hoy, 13-26. Madrid: Rialp, 1983. 
Sánchez, Enrique. "Carta de López Obrador a España, propuesta de reconciliación histórica: Ebrard.” Excélsior, 27 de marzo de 2019. https://www.excelsior.com. $\mathrm{mx} /$ nacional/carta-de-lopez-obrador-a-espana-propuesta-de-reconciliacion-historica-ebrard/1304129.

Tejeda, Armando. "Petición de AMLo desata orgullo patrio e insultos racistas en España." La Jornada, 26 de marzo de 2019. Acceso el 29 de septiembre de 2019. https://www.jornada.com.mx/ultimas/politica/2019/03/26/peticion-de-amlo-desata-orgullo-patrio-en-espana-6785.html.

Wulff, Fernando. Las esencias patrias. Historiografía e historia antigua en la construcción de la identidad española (siglos XVI-XIX). Madrid: Crítica, 2003.

\section{SOBRE EL AUTOR}

Licenciado en Historia por la Facultad de Filosofía y Letras de la UNAM. Cursó la maestría y el doctorado en el Departamento de Historia Medieval de la Universidad Complutense de Madrid, donde obtuvo el grado en 2007. Es investigador de tiempo completo del Instituto de Investigaciones Históricas de la UNAM y profesor de la licenciatura y el posgrado en Historia de la misma universidad. Sus líneas de investigación están centradas en la historiografía española de la época medieval, moderna y contemporánea, y en la legitimación de la guerra de conquista en la península ibérica durante la Edad Media y los primeros años de la conquista de América. En la actualidad realiza la biografía intelectual del medievalista español Claudio Sánchez-Albornoz. Una de sus más recientes publicaciones es "De Europa a América: Claudio Sánchez-Albornoz y la fundación de los Cuadernos de Historia de España’”, Medievalismo, n. 28 (2018). 